Gut, 1966, 7, 593

\title{
Kinetic studies of the epithelial cells of the rectal mucosa in normal subjects and patients with ulcerative colitis ${ }^{1}$
}

\author{
ROY G. SHORTER, ROBERT J. SPENCER, AND GEORGE A. HALLENBECK \\ From the Sections of Experimental and Anatomic Pathology, Proctology, and of Surgery, \\ the Mayo Clinic and Mayo Foundation, Rochester, Minnesota, U.S.A.
}

\begin{abstract}
EDITORIAL COMMENT Besides its interest in providing further data on the turnover time of the rectal epithelium in normal subjects, this study shows that the mitotic duration or the turnover time is prolonged in active colitis. This finding should provide a stimulus to further kinetic studies in this disease.
\end{abstract}

Relatively few reports of studies of the cytodynamics in the epithelia in the gastrointestinal tract in humans have appeared in the literature in contrast to the numerous descriptions of studies carried out in experimental animals. From the reports that are available, it is apparent that the normal results given for human subjects have mostly been obtained from studies of the gastrointestinal epithelia in patients with carcinomatosis in which a reasonable assumption was made that the observations represented normality (Cole and McKalen, 1961; Lipkin, Bell, and Sherlock, 1963; Shorter, Moertel, Titus, and Reitemeier, 1964). With this assumption in mind, Cole and McKalen (1961) found an epithelial cellular turnover time of six to eight days in the rectal mucosa in an elderly patient with a colonic carcinoma. Making the same assumption, Lipkin et al. (1963), from a study of two patients with carcinomatosis, concluded that the turnover time in the rectal epithelium was three to four days, and similar observations were made by Shorter et al. (1964).

In a study of normal and abnormal human rectal mucosa, Deschner, Lewis, and Lipkin (1963), using an in vitro technique, found differences in the incorporation of tritium-labelled thymidine and the proliferation of epithelial cells between the rectal mucosa of normal subjects and that of patients with multiple polyposis.

The purpose of this communication is to report the findings of a study of the kinetics of the rectal mucosae in a series of normal subjects, in patients with active chronic ulcerative colitis, and in patients

${ }^{1}$ This investigation was supported in part by research grant CA-06872 from the National Institutes of Health, Public Health Service. with chronic ulcerative colitis in remission. The technique of mitotic counting and a method in vitro of nuclear with tritium-labelled thymidine were used.

\section{MATERIALS AND METHODS}

Biopsy samples were obtained at proctoscopic examination of 18 normal subjects, ranging in age from 9 to 70 years, of whom five were males and 13 females. Each decade was represented in the group. The patients were not fasting at the time of the proctoscopic examination and had received warm tap water enemata within the previous one to three hours to ensure good visualization of the mucosa. All the biopsy samples were taken from $10 \mathrm{~cm}$. above the dentate level by means of Buie forceps. All the examinations were made between the hours of 8 and 10.30 a.m., and none of the patients was anaesthetized. The tissues obtained were placed immediately in $5 \mathrm{ml}$. of T.C.199 (Gibco Biological Company, Grand Island, New York) containing $1 \mu \mathrm{c}$. per millilitre of tritium-labelled thymidine (Volk Radiochemical Corp.; specific activity, $6.7 \mathrm{c} / \mathrm{mM}$ ) and incubated for one hour at a temperature of $37^{\circ} \mathrm{C}$. At the end of this period the tissues were washed in T.C.199 and fixed immediately in $10 \%$ neutral formalin. After the tissue was embedded in paraffin wax, multiple sections were cut at a thickness of $3 \mu$, and autoradiographs were prepared with liquid emulsion (Kodak; NTB 2). After exposure for five to six weeks in light-tight boxes at the temperature of domestic refrigeration, the autoradiographs were developed, stained with haematoxylin and eosin, and examined with light microscopy. For the calculation of the mitotic indices, counts were made, by means of high-dry and high-oil immersion objectives, of the number of crypts studied in each specimen, of the total number of epithelial cells in each crypt, and of the total number of cells in each crypt in all phases of mitosis. Only crypts cut in 
longitudinal section were included. An average of 1,000 cells was counted in each specimen. From these counts, the mean turnover time for each specimen was calculated from the mitotic indices (turnover time = mitotic duration/mitotic index), with the assumption that the mitotic duration (M) was one hour (Leblond, 1959; Lipkin, 1965). In addition to the calculation of the mitotic index, counts were made of the number of epithelial cells showing nuclear labelling in each crypt, and no cell was considered to show labelling unless at least five grains were present over the nucleus. From these observations, the percentage of cells showing nuclear labelling was estimated and the sites of the labelled cells in the crypts also were recorded.

Biopsy samples of rectal mucosa were obtained in a similar fashion from nine patients with chronic ulcerative colitis in whom a clinical and histological diagnosis had been made previously but in whom, at the time of this study, there was no clinical activity or proctological or pathological evidence of ulceration. The ages of these patients, six women and three men, ranged from $2 \frac{1}{2}$ to 59 years. The tissues were obtained, treated, and studied in a manner identical to that described for the normal subjects.

Biopsy samples were obtained from the rectal mucosae of 17 patients with clinical, proctological, and histological evidence of active chronic ulcerative colitis. Samples were selected from apparently intact and non-polypoidal zones of mucous membrane between the areas of ulceration. The ages of these patients, nine women and eight men, ranged from 12 to 77 years. None of the patients were receiving active therapy, including steroids, at the time of sampling. The tissues were obtained, handled, and studied in a manner identical to that described for the tissues from normal subjects.

\section{RESULTS}

GENERAL OBSERVATIONS The histological appearances were normal in the rectal mucosae from all the clinically normal subjects. The histological findings were normal in the rectal mucosae from patients with ulcerative colitis in remission except for the presence of increased numbers of chronic inflammatory cells in the mucosa, including a relatively high percentage of eosinophilic leucocytes. The histological appearances in the non-ulcerated areas of rectal mucosa from patients with clinically active chronic ulcerative colitis included the presence of acute and subacute inflammation, with occasional early crypt abscesses, and were compatible with a histological diagnosis of chronic ulcerative colitis. In the rectal mucosa from the normal subjects and from the two groups of patients with chronic ulcerative colitis, mitotic figures were seen only in the basal two-thirds of the rectal crypts.

In all groups, labelling of nuclei of epithelial cells, when present, was confined largely to cells at the base of the crypts. However, occasional crypt-neck cells also showed nuclear labelling, but this was rare, and such labelling was seen equally in all groups. No mitotic figures were seen in these cells.

Within each clinical group, there were no significant differences related to age or sex; therefore, such divisions within each clinical group were ignored and the results are considered together.

NORMAL SUBJECTS From the mitotic indices, the mean turnover time of the rectal epithelium was found to be 3.66 days with a standard error of 0.42 , based on the results obtained in each of the samples. Labelling of epithelial cellular nuclei (Fig. 1) was achieved in only 15 of the 18 samples. The mean percentage of epithelial cells showing nuclear labelling after one hour of incubation was $1 \cdot 53$, with a standard error of $\mathbf{0} \cdot 12$. No labelled mitotic figures were found in any specimen.

PATIENTS WITH CHRONIC ULCERATIVE COLITIS IN REMISSION From the mitotic indices, the mean turnover time of the rectal epithelium in these subjects was 4.73 days with a standard error of 0.59 , based on

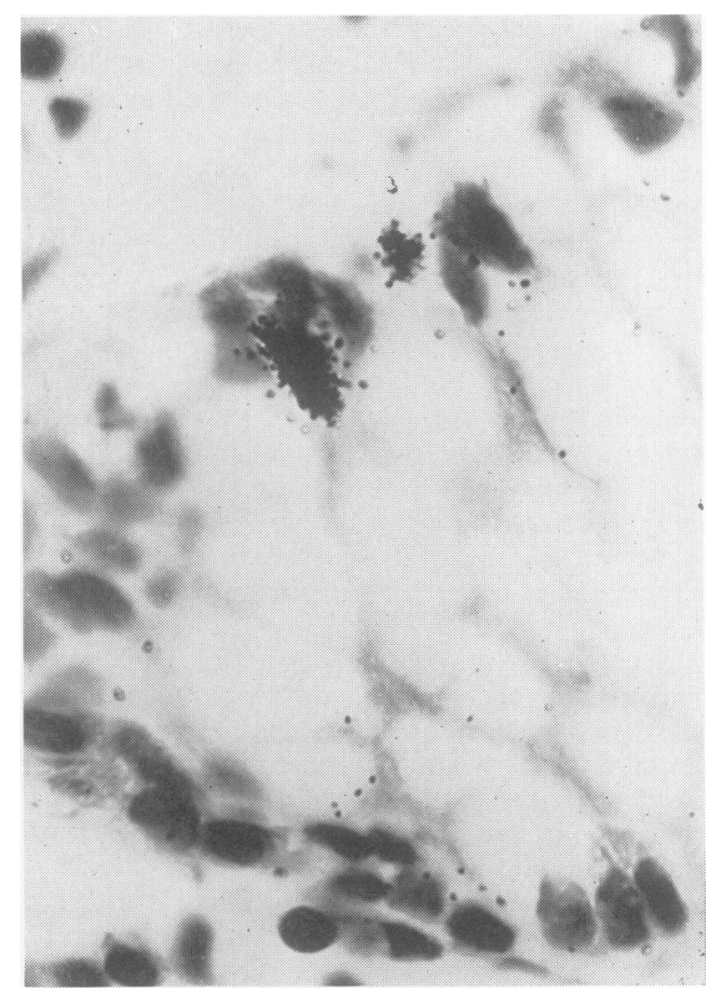

FIG. 1. Nuclear labelling of epithelial cell can be seen in base of a crypt in rectal mucosa from a normal subject. (Haematoxylin and eosin $\times 1,200$.) 


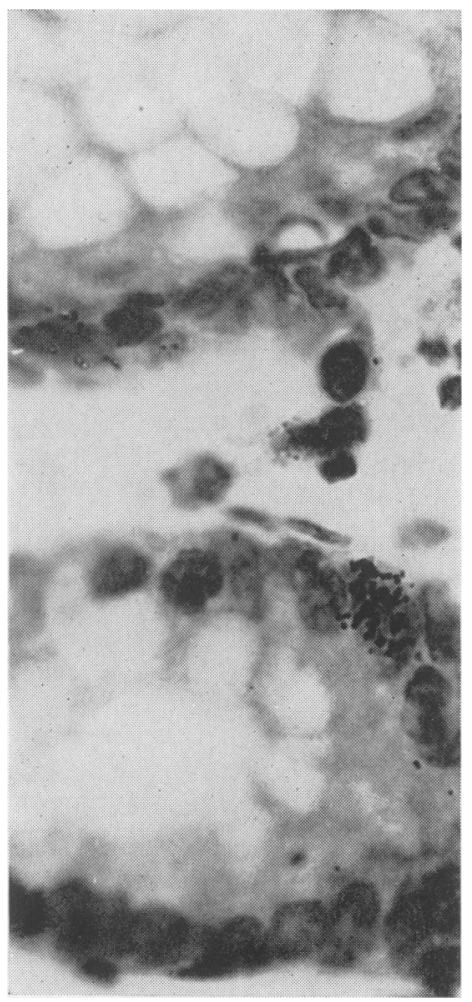

FIG. 2. Nuclear

labelling of an epithelial cell can be seen in the crypt in rectal mucosa from a patient with active ulcerative colitis (Haematoxylin and eosin $\times 1,120$.)

the results obtained in each of the samples. Nuclear labelling was achieved in only seven of the nine samples, and the mean percentage of labelled cells was 1.05 with a standard error of 0.60 . No labelled mitotic figures were seen. Neither turnover time nor percentages of labelled cells were different significantly from the results obtained in the normal subjects when Student's t test was applied.

PATIENTS WITH ACTIVE CHRONIC ULCERATIVE COLITIS From the mitotic indices, the mean turnover time of the rectal epithelium in these patients was 5.45 days with a standard error of 0.61 , based on the results obtained in each of the samples. This figure was significantly different from the findings in the normal subjects when Student's $t$ test was applied $(P>0.02)$. Nuclear labelling of epithelial cells (Fig. 2) was achieved in all samples, and the mean percentage of nuclear labelling was 1.65 with a standard error of $0 \cdot 65$. This figure was not significantly different from that obtained in the normal subjects when Student's $t$ test was applied.

The results are summarized in the Table.

\section{COMMENT}

As Lipkin (1965) has indicated, under normal

\section{TABLE}

TURNOVER TIMES OF RECTAL EPITHELIUM OF NORMAL SUBJECTS AND OF PATIENTS WITH INACTIVE AND ACTIVE CHRONIC ULCERATIVE COLITIS

\begin{tabular}{|c|c|c|c|c|}
\hline & No. & $\begin{array}{l}\text { Mean Turnover } \\
\text { Time (days) }\end{array}$ & & $P$ Value \\
\hline $\begin{array}{l}\text { Normal subjects } \\
\text { Chronic ulcerative colitis in } \\
\text { remission } \\
\text { Chronic ulcerative colitis } \\
\text { active }\end{array}$ & $\begin{array}{r}18 \\
9 \\
17\end{array}$ & $\begin{array}{l}3.66 \pm 0.42^{1} \\
4.73 \pm 0.59 \\
5.45 \pm 0.61\end{array}$ & 0.1 & 0.02 \\
\hline
\end{tabular}

${ }^{1}$ Mean \pm S.E.

circumstances it is likely that the mitotic index is a fairly accurate reflection of the turnover time, and in diseased tissues this could similarly be true. Our finding of a turnover time of $\mathbf{3 . 6 6}$ days in the epithelium of the rectal mucosa in normal human subjects is in agreement with the findings of Lipkin et al. (1963) and Shorter et al. (1964), who, using a technique in vivo with tritium-labelled thymidine, estimated the time to be three to four days in patients with carcinomatosis. If the mitotic duration is assumed to be normal, then the turnover time in the rectal mucosa of patients with active chronic ulcerative colitis is prolonged significantly and, with the same assumption, the turnover time is within normal limits in remission. If this finding is confirmed by others, obviously its ultimate significance must await the quantitation of the actual mitotic duration in the epithelial cells in the rectal mucosa in active chronic ulcerative colitis since, with our method, any significant alteration in this duration would influence profoundly the turnover time. Till now, however, only slight alterations in mitotic duration have been observed in some diseased tissues (Lipkin, 1965). Whereas it is gratuitous to speculate at this point, if the slow turnover time proves to be a true finding in active chronic ulcerative colitis, it is likely that this would prove a significant base line for further experiments into the pathogenesis of this disease.

In considering the quantitative results obtained from the incubation in vitro with tritium-labelled thymidine, since radio-labelling of epithelial cellular nuclei was not achieved in some specimens and in all instances the incidence of labelling was low, presumably because of technical limitations of diffusion of the isotope into solid tissues in situations in vitro, we find it difficult to comment on the observed low incidence of nuclear labelling in epithelial cells at the end of one hour of incubation or to comment on the apparent lack of significant differences in labelling between the mucosa in normal patients and those with quiescent or active ulcerative colitis. However, if our findings are valid, they would indicate that a similarly-sized epithelial-cellular 
population is entering the phase of synthesis of desoxyribonucleic acid (S phase) in all the groups. The interpretation of the significance of this finding in relation to the prolonged turnover time in the mucosa from patients with active ulcerative colitis must await the outcome of further experiments to see if these results can be confirmed and extended. It is noteworthy that the percentage of labelled cells in all groups was approximately the same as that observed by Deschner et al. (1963) in rectal mucosae from normal subjects at the end of a similar period of incubation in vitro. Qualitatively the finding of epithelial cells showing nuclear labelling in the crypt neck in specimens from normal subjects and patients with ulcerative colitis is significant in itself since it suggests the existence of two populations of epithelial cells in the rectal mucosa. The importance of the recognition of this double population is emphasized by the observations of Deschner et al. (1963) who noted significant differences from normality in the site of labelling in the rectal crypts in patients with multiple polyposis. In this condition labelling of surface cells and cells lining the upper parts of the crypts was a prominent feature, in marked contrast to normal mucosa in which labelling was confined to the base of the crypts. These workers suggested that the existence of a fast-moving cellular population at the tips of the crypts might perpetuate the polypoid tissue by continued outgrowth or budding.

\section{SUMMARY}

The kinetics of the epithelial cells of the rectal mucosa were studied in normal subjects and patients with active chronic ulcerative colitis and patients with chronic ulcerative colitis in remission by means of the technique of mitotic counting and a method of nuclear labelling in vitro with tritium-labelled thymidine.

In normal subjects, the mean turnover time in the rectal epithelium was 3.66 days. In patients with chronic ulcerative colitis in remission, the mean turnover time was 4.73 days, a figure that was not statistically different from normal. In patients with active chronic ulcerative colitis, the mean turnover time was 5.45 days, a figure that was significantly different from the findings in normal subjects $(P<0.02)$.

Qualitative assessment of the distribution of cells showing nuclear labelling in the rectal glands suggested the existence of two populations of epithelial cells. The possible significance of these findings is discussed.

Our thanks are due to Mrs. Virginia Knopf for technical assistance.

\section{REFERENCES}

Cole, J. W., and McKalen, A. (1961). Observations of cell renewal in human rectal mucosa in vivo with thymidine- $\mathrm{H}_{3}$. Gastroentero$\log y, 41,122-125$.

Deschner, E., Lewis, C. M., and Lipkin, M. (1963). In vitro study of human rectal epithelial cells. I. Atypical zone of $\mathbf{H}^{3}$ thymidine incorporation in muccsa of multiple polyposis. J. clin. Invest., 42, 1922-1928.

Leblond, C. P. (1959). Classical techniques for the study of the kinetics of cellular proliferation. In The Kinetics of Cellular Proliferation: Conference on Fundamental Problems and Technics for the Study of the Kinetics of Cellular Proliferation, edited by F. Stohlman, pp. 31-47. Grune and Stratton, New York.

Lipkin, M. (1965). Cell proliferation in the gastrointestinal tract in man. Fed. Proc., 24, 10-15.

Lipkin, M., Bell, B., and Sherlock, P. (1963). Cell proliferation kinetics in the gastrointestinal tract of man. I. Cell renewal in colon and rectum. $J$. clin. Invest., 42, 767-776.

Shorter, R. G., Moertel, C. G., Titus, J. L., and Reitemeier, R. J. (1964). Cell kinetics in the jejunum and rectum of man. Amer. J. dig. Dis., 9, 760-763. 